(C) The Authors 2015. This is an Open Access article, distributed under the terms of the Creative Commons Attribution licence (http:// creativecommons.org/licenses/by/3.0/), which permits unrestricted re-use, distribution, and reproduction in any medium, provided the original work is properly cited.

\title{
The influence of birth order and number of siblings on adolescent body composition: evidence from a Brazilian birth cohort study
}

\author{
Fernanda de Oliveira Meller ${ }^{1 *}$, M. C. F. Assunção ${ }^{1}$, A. A. Schäfer ${ }^{1}$, C. L. de Mola $^{1}$, A. J. D. Barros ${ }^{1}$, \\ D. L. Dahly ${ }^{2}$ and F. C. Barros ${ }^{1}$ \\ ${ }^{1}$ Post-Graduate Program in Epidemiology, Federal University of Pelotas, Pelotas, Brazil \\ ${ }^{2}$ Department of Epidemiology and Public Health, University College Cork, Cork, Republic of Ireland
}

(Submitted 3 December 2014 - Final revision received 7 March 2015 - Accepted 9 April 2015 - First published online 15 June 2015)

\begin{abstract}
The aim of this study was to estimate the association between birth order and number of siblings with body composition in adolescents. Data are from a birth cohort study conducted in Pelotas, Brazil. At the age of 18 years, 4563 adolescents were located, of whom 4106 were interviewed (follow-up rate $81.3 \%$ ). Of these, 3974 had complete data and were thus included in our analysis. The variables used in the analysis were measured during the perinatal period, or at 11, 15 and/or 18 years of age. Body composition at 18 years was collected by air displacement plethysmography (BOD POD ${ }^{\circledR}$ ). Crude and adjusted analyses of the association between birth order and number of siblings with body composition were performed using linear regression. All analyses were stratified by the adolescent sex. The means of BMI, fat mass index and fat-free mass index among adolescents were 23.4 (sD 4.5$) \mathrm{kg} / \mathrm{m}^{2}, 6 \cdot 1$ (sD 3.9$) \mathrm{kg} / \mathrm{m}^{2}$ and $17 \cdot 3(\mathrm{sD} 2 \cdot 5) \mathrm{kg} / \mathrm{m}^{2}, \mathrm{respect}-$ ively. In adjusted models, the total siblings remained inversely associated with fat mass index $(\beta=-0.37 z$-scores, $95 \% \mathrm{CI}-0 \cdot 52,-0 \cdot 23)$ and BMI in boys $(\beta=-0.39 z$-scores, $95 \% \mathrm{CI}-0.55,-0.22)$. Fat-free mass index was related to the total siblings in girls $(\beta=0.06$ $z$-scores, $95 \%$ CI $-0.04,0.17)$. This research has found that number of total siblings, and not birth order, is related to the fat mass index, fat-free mass index and BMI in adolescents. It suggests the need for early prevention of obesity or fat mass accumulation in only children.
\end{abstract}

Key words: Birth order: Siblings: Body composition: Adolescents: Cohort studies

Like most places in the world, the total fertility rate in Brazil is low, and continuing to decline. The average number of births per woman was $2 \cdot 3$ in the year 2000 and 1.9 in $2010^{(1,2)}$ Recent studies suggest that the consequent changes in family structure may influence obesity risk in adolescence ${ }^{(3,4)}$. Some have observed that only children have higher BMI, greater fat mass, and are more likely to be overweight or obese ${ }^{(5-7)}$. The influence of birth order on the occurrence of obesity has also been investigated, but the findings are inconsistent in previous studies. While some authors showed higher BMI and greater fat mass between firstborn adolescents ${ }^{(8-11)}$, others have not observed such associations ${ }^{(6,12,13)}$. Studies have also shown that a larger number of siblings is associated with lower prevalence of obesity in adolescence ${ }^{(3,4)}$, regardless of whether siblings are younger or older ${ }^{(4)}$.

There are both social and biological explanations of how birth order and/or number of siblings might influence adolescent body composition. Lower-birth-order infants tend to be smaller at birth than later-born infants ${ }^{(14-16)}$ and more likely to experience catch-up growth, a pattern of growth associated with obesity risk ${ }^{(13)}$. However, lower-birth-order children also tend to have fewer siblings, which might reduce their opportunities for playing games and other physical activities ${ }^{(17)}$. It is thus critically important to better understand the relative importance of both birth order and number of siblings, a challenge few previous studies have addressed.

To help fill this gap, we used data from the 1993 Birth Cohort of Pelotas, Brazil, which included detailed information on family structure, to evaluate the association between both birth order and number of siblings with body composition in 18-year-old adolescents.

\section{Methods}

\section{Study design and sample}

Data are from a population-based birth cohort study located in Pelotas, Brazil. Between 1 January and 30 December, 1993, all maternity hospitals in the city were visited daily and 5265 births from woman living in the city were recorded. Of this, 5249 agreed to take part in the longitudinal study. Mothers and their infants have since been followed up on numerous occasions. Visits to the full cohort took place at 11, 15 and 18 years of age. Topic-specific sub-studies were conducted 
at the ages of $4,6,9,11,13$ and 18 years. More detailed information about the study can be found in specific methodological publications ${ }^{(18,19)}$.

To be included in the sample used in this analysis, individuals must have participated in the follow-ups at ages 11, 15 and 18 years, and have information on the perinatal exposures (birth order), at age 15 years (number of younger siblings and total siblings) and on the outcomes at age 18 years (BMI, fat mass and fat-free mass). Individuals who at 18 years of age were pregnant or suspected of being pregnant, in a cast, or using a wheelchair were excluded from the sample.

\section{Measurements}

Body composition at 18 years of age was assessed by fat mass index (fat mass in $\mathrm{kg}$ divided by height in $\mathrm{m}^{2}$ ) and fat-free mass index (fat-free mass in $\mathrm{kg}$ divided by height in $\mathrm{m}^{2}$ ), both collected by air displacement plethysmography (BOD POD $^{\circledR}$ ), using the Siri equation. These indices include the height of the individual in the calculations, and thus improving interpretation in adolescents with different heights ${ }^{(20)}$. Moreover, the BMI (weight in $\mathrm{kg}$ divided by height in $\mathrm{m}^{2}$ ) was also assessed at the age of 18 years.

For the examination, the young individuals were attired in a top and shorts made of average compression spandex, and a silicone cap with good grip on the head.
Height was measured using an aluminium stadiometer with size of $2 \mathrm{~m}$ and precision of $1 \mathrm{~mm}$; and weight was measured with an electronic scale connected to the BOD POD ${ }^{\circledR}$. All measurements were taken by trained interviewers.

Data collection on major exposures was performed by asking the mother two questions. For data on birth order, we asked 'How many times have you ever been pregnant including this pregnancy?', and to collect information on number of younger siblings, we asked 'Have you had any children after (name)? How many?' Then, the two responses were combined to build the total siblings variable.

The first question was made during the perinatal follow-up, and the second at the 15-year-old follow-up.

\section{Analytical methods}

The main exposures used in the analyses were birth order (dummy-variable coded as first born, 0; second born, 1; third born, 2; and fourth born or more, 3), number of younger siblings and total siblings (each dummy-variable coded for 0 , 1, 2, and more than 3 siblings). The outcomes BMI, fat mass index and fat-free mass index were assessed as continuous variables in $\mathrm{kg} / \mathrm{m}^{2}$ and standardised as $z$-scores.

For controlling possible confounding factors, the following variables were included in the analysis: family income (in minimum wages), maternal education (in completed years),

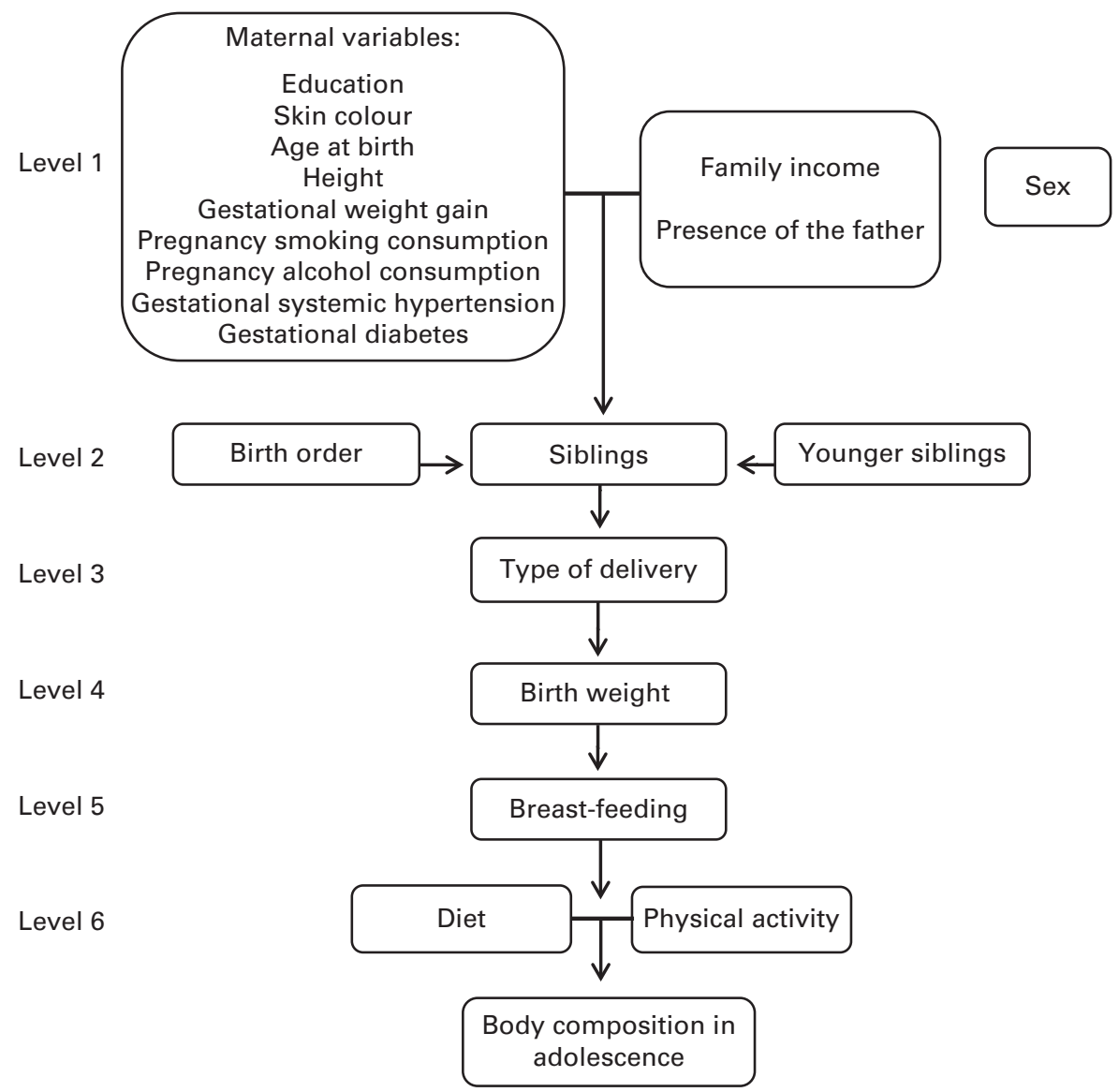

Fig. 1. Conceptual model of association between birth order, number of siblings and body composition at 18 years of age. The 1993 Pelotas Birth Cohort, Brazil. 
presence of the father (yes/no), maternal skin colour (white) black/other), maternal age at birth (in years), maternal height (in $\mathrm{cm}$ ), gestational weight gain (in g), pregnancy smoking consumption (yes/no), pregnancy alcohol consumption (yes/no), gestational systemic hypertension (yes/no) and gestational diabetes (yes/no).

At the age of 18 years, 4563 adolescents were located, of whom 4106 were interviewed and 3974 adolescents were included in our analysis with complete data on body composition. Those who completed the interviews, added to those known to have died, represented $81.3 \%$ of the original cohort. Of those located, $127(2.3 \%)$ refused to participate in the study and $330(7 \cdot 2 \%)$ were considered losses, 196 were found living in other cities and were not interviewed. The maternal height variable had the maximum percentage of unknown observations (7.9\%).

Descriptive analysis of the exposures and outcomes were performed, presenting the absolute and relative frequencies of categorical variables, and measures of central tendency and dispersion for continuous variables.

Table 1. Characteristics of sample according to the variables studied (The 1993 Pelotas Birth Cohort, Brazil) (Number of participants and percentages; mean values and standard deviations; median values and interquartile ranges (IQR))

\begin{tabular}{|c|c|c|c|c|c|c|}
\hline \multirow[b]{2}{*}{ Variables } & \multicolumn{2}{|c|}{ Total } & \multicolumn{2}{|c|}{ Male } & \multicolumn{2}{|c|}{ Female } \\
\hline & $n$ & $\%$ & $n$ & $\%$ & $n$ & $\%$ \\
\hline \multicolumn{7}{|l|}{ Birth order } \\
\hline First born & 1634 & 39.8 & 791 & $39 \cdot 3$ & 843 & $40 \cdot 4$ \\
\hline Second & 1225 & 29.9 & 603 & 29.9 & 622 & 29.8 \\
\hline Third & 652 & $15 \cdot 9$ & 311 & $15 \cdot 4$ & 341 & $16 \cdot 3$ \\
\hline Fourth or later & 592 & 14.4 & 311 & $15 \cdot 4$ & 281 & 13.5 \\
\hline \multicolumn{7}{|l|}{ Younger siblings } \\
\hline 0 & 1621 & 41.5 & 770 & $41 \cdot 2$ & 851 & $42 \cdot 0$ \\
\hline 1 & 1300 & 33.4 & 617 & 33.0 & 683 & 33.7 \\
\hline 2 & 545 & $14 \cdot 0$ & 286 & $15 \cdot 3$ & 259 & $12 \cdot 8$ \\
\hline$\geq 3$ & 431 & $11 \cdot 1$ & 197 & 10.5 & 234 & 11.5 \\
\hline \multicolumn{7}{|l|}{ Total siblings } \\
\hline 0 & 470 & $12 \cdot 1$ & 216 & $11 \cdot 6$ & 254 & $12 \cdot 5$ \\
\hline 1 & 1198 & $30 \cdot 8$ & 560 & $30 \cdot 0$ & 638 & 31.6 \\
\hline 2 & 963 & $24 \cdot 7$ & 466 & $25 \cdot 0$ & 497 & 24.5 \\
\hline$\geq 3$ & 1263 & 32.4 & 626 & 33.4 & 637 & 31.4 \\
\hline \multicolumn{7}{|l|}{ Maternal skin colour } \\
\hline White & 3155 & 76.9 & 1562 & 77.4 & 1593 & $76 \cdot 3$ \\
\hline Black & 763 & $18 \cdot 6$ & 361 & 17.9 & 402 & $19 \cdot 3$ \\
\hline Other & 186 & 4.5 & 95 & 4.7 & 91 & 4.4 \\
\hline \multicolumn{7}{|l|}{ Pregnancy smoking consumption } \\
\hline Yes & 1349 & 32.9 & 644 & 31.9 & 705 & 33.8 \\
\hline No & 2757 & $67 \cdot 1$ & 1374 & $68 \cdot 1$ & 1383 & $66 \cdot 2$ \\
\hline \multicolumn{7}{|l|}{ Pregnancy alcohol consumption } \\
\hline Yes & 212 & $5 \cdot 2$ & 91 & 4.5 & 121 & $5 \cdot 8$ \\
\hline No & 3894 & $94 \cdot 8$ & 1927 & 95.5 & 1967 & 94.2 \\
\hline \multicolumn{7}{|l|}{ Gestational systemic hypertension } \\
\hline Yes & 631 & $15 \cdot 7$ & 332 & $16 \cdot 8$ & 299 & 14.6 \\
\hline No & 3398 & $84 \cdot 3$ & 1645 & 83.2 & 1753 & $85 \cdot 4$ \\
\hline \multicolumn{7}{|l|}{ Gestational diabetes } \\
\hline Yes & 108 & $2 \cdot 7$ & 51 & $2 \cdot 6$ & 57 & $2 \cdot 8$ \\
\hline No & 3911 & $97 \cdot 3$ & 1918 & 97.4 & 1993 & $97 \cdot 2$ \\
\hline \multicolumn{7}{|l|}{ Presence of the father } \\
\hline Yes & 3618 & $88 \cdot 1$ & 1766 & 87.5 & 1852 & 88.7 \\
\hline No & 488 & 11.9 & 252 & $12 \cdot 5$ & 236 & $11 \cdot 3$ \\
\hline Maternal education (completed years) & 4099 & & 2014 & & 2085 & \\
\hline Mean & $6 \cdot 8$ & & $6 \cdot 8$ & & $6 \cdot 7$ & \\
\hline SD & 3.5 & & 3.5 & & 3.5 & \\
\hline Maternal age at birth (years) & 4105 & & 2017 & & 2088 & \\
\hline Mean & $26 \cdot 1$ & & $26 \cdot 1$ & & $26 \cdot 1$ & \\
\hline SD & $6 \cdot 4$ & & 6.5 & & $6 \cdot 3$ & \\
\hline Maternal height* $(\mathrm{cm})$ & 3780 & & 1832 & & 1948 & \\
\hline Mean & $157 \cdot 7$ & & $157 \cdot 6$ & & $157 \cdot 8$ & \\
\hline SD & $6 \cdot 7$ & & $6 \cdot 3$ & & $7 \cdot 0$ & \\
\hline Gestational weight gain (g) & 3953 & & 1940 & & 2013 & \\
\hline Mean & $11 \cdot 7$ & & 11.9 & & 11.6 & \\
\hline SD & 5.9 & & 5.9 & & $5 \cdot 8$ & \\
\hline Family income (MMW) & 4035 & & 1989 & & 2046 & \\
\hline Median & $2 \cdot 6$ & & $2 \cdot 5$ & & $2 \cdot 8$ & \\
\hline IQR & $1.5-4.6$ & & $1.5-4.5$ & & $1.5-4.8$ & \\
\hline
\end{tabular}

MMW, monthly minimum wages.

* Maximum percentage of unknown observations: $(n 326 ; 7.9 \%)$ for the maternal height variable. 
Later, linear regression models were used to estimate associations between exposures (birth order, number of younger siblings and total siblings) and outcomes (BMI, fat mass index and fat-free mass index). We report crude estimates, as well as those adjusted for the potential confounders described earlier. All analyses were sex stratified.

To evaluate the relative importance of birth order and number of siblings, we compared the fit of three different models based on their respective $R^{2}$, adjusted $R^{2}$, Akaike's information criterion and mean squared error. In model 1 , only birth order and number of younger siblings were included as independent variables. In model 2, we included these variables plus potential confounders (Fig. 1). Model 3 included the total siblings (which is equal to the birth order plus the number of younger siblings, less one), and the confounding variables of model 2. The purpose of this third model was to evaluate if the position of the adolescent in the family influences the body composition, or whether this association is rather due to the number of siblings. The model that presented the best fit was the one with higher values of $R^{2}$ and adjusted $R^{2}$, and lower values of Akaike's information criterion and mean squared error.

\section{Ethical considerations}

The present study is part of the 18-year-old follow-up in the 1993 birth cohort, titled Early and contemporary influences on body composition, human capital, mental health and complex chronic diseases precursors in the 1993 birth cohort of Pelotas, Brazil', which was approved by the Ethics Committee of the Medicine School of the Federal University of Pelotas in the official letter numbered 05/11.

All participants signed an informed consent form before the procedures, interviews and examinations in both follow-ups. At the age of 18 years, body composition examinations did not present health risks to participants; nevertheless, girls were always asked about the possibility of pregnancy. Pregnant women and those suspected of being pregnant did not perform the tests

\section{Results}

Characteristics of sample studied are shown in Table 1 . Most of the adolescents were the firstborns (39.8\%), and at the age of $15,30 \cdot 8 \%$ had one sibling. Regarding the presence of the father, $11.9 \%$ of adolescents had no father living in the house when they were born. In relation to the mothers, one-third reported smoking during pregnancy (32.9\%) and a small proportion reported drinking alcohol during pregnancy $(5 \cdot 2 \%)$. The average maternal education at birth was about 7 (SD 3.5) years and maternal age at birth was 26 (SD 6.4) years on average. The median family income was 2.6 times (interquartile range 1.5-4.6) the minimum wage.

Table 2 shows the mean and standard deviations of BMI, fat mass index and fat-free mass index among male and female adolescents, and in the total population. These averages were $23.4(\mathrm{sD} \quad 4.5) \mathrm{kg} / \mathrm{m}^{2}, \quad 6.1 \quad(\mathrm{SD} \quad 3.9) \mathrm{kg} / \mathrm{m}^{2}$ and 17.3 (SD 2.5$) \mathrm{kg} / \mathrm{m}^{2}$, respectively. Although BMI was the same for both sexes, girls had an average fat mass index almost two times higher than boys, while the mean fat-free mass index was higher in males. The prevalence of overweight and obesity in the adolescents, using the BMI-for-age WHO criterion, was $17 \cdot 2(95 \%$ CI $16 \cdot 0,18 \cdot 3) \%$ and $10 \cdot 1$ (95\% CI $9 \cdot 2$, $11 \cdot 0) \%$, respectively.

Table 3 presents the fit of the three models analysed, for each of the three outcomes investigated. In general, model 3 showed the best fit for each outcome, and was more parsimonious than model 2 . While models 1 and 2 indicated that both birth order and number of younger siblings were associated with the outcome (data not shown), the better fit of model 3 led us to conclude that the total siblings was the key influence on fat mass index, fat-free mass index and BMI, rather than the position that the adolescents occupy among siblings.

The distributions of BMI, fat mass index and fat-free mass index, across total siblings, by sex are presented in Fig. 2. Boys who had three or more siblings had lower BMI mean (22.6, 95\% CI 22.3, 22.9) compared to those of only children (24.4, 95\% CI $23 \cdot 8,25 \cdot 1)$. Fat mass index was associated to total siblings in both sexes. Adolescents with three or more siblings had lower fat mass index mean than those who had no siblings. Girls who had three or more siblings had higher fat-free mass index mean $(15 \cdot 7,95 \%$ CI $15 \cdot 5,15 \cdot 8)$ than those who had none $(15 \cdot 3,95 \%$ CI $15 \cdot 1,15 \cdot 5)$.

Table 4 shows the crude and adjusted analyses of the association between total siblings and the outcomes studied according to sex. After adjustment for possible confounders (family income, maternal education, presence of the father, maternal skin colour, maternal age at birth, maternal height, gestational weight gain, pregnancy smoking consumption, pregnancy alcohol consumption, gestational systemic hypertension and gestational diabetes), the total siblings remained associated with fat mass index in both sexes with an inverse

Table 2. Description of the sample according to outcomes studied (The 1993 Pelotas Birth Cohort, Brazil)

(Mean values and standard deviations)

\begin{tabular}{lrrrrrrrr}
\hline & \multicolumn{2}{c}{ Total $(n$ 3974) } & & \multicolumn{2}{c}{ Male $(n$ 1973) } & & \multicolumn{2}{c}{ Female $(n$ 2001) } \\
\cline { 2 - 3 } Variables & Mean & SD & & Mean & SD & & Mean & SD \\
\hline BMI $\left(\mathrm{kg} / \mathrm{m}^{2}\right)$ & 23.4 & 4.5 & & 23.4 & 4.2 & & 23.5 & 4.8 \\
Fat mass index $\left(\mathrm{kg} / \mathrm{m}^{2}\right)$ & 6.1 & 3.9 & & 4.2 & 3.1 & & 8.0 & 3.6 \\
Fat-free mass index $\left(\mathrm{kg} / \mathrm{m}^{2}\right)$ & 17.3 & 2.5 & & 19.1 & 1.9 & & 15.5 & 1.6 \\
\hline
\end{tabular}


Table 3. Evaluation of the goodness of fit of analysed models (The 1993 Pelotas Birth Cohort, Brazil)

\begin{tabular}{|c|c|c|c|c|c|}
\hline & $n$ & $R^{2}$ & Adjusted $R^{2}$ & AIC & MSE \\
\hline \multicolumn{6}{|c|}{ Outcome: fat mass index } \\
\hline Model $1^{*}$ & 3788 & 0.01 & 0.01 & $10720 \cdot 28$ & 1.00 \\
\hline Model $2 \dagger$ & 3345 & 0.02 & 0.01 & 9471.34 & 0.99 \\
\hline Model 3‡ & 3345 & 0.02 & 0.01 & $9465 \cdot 31$ & 0.99 \\
\hline \multicolumn{6}{|c|}{ Outcome: fat-free mass index } \\
\hline Model $1^{*}$ & 3788 & 0.003 & 0.002 & $10777 \cdot 17$ & 1.00 \\
\hline Model $2 \dagger$ & 3345 & 0.02 & 0.01 & 9503.96 & 1.00 \\
\hline Model 3ł & 3345 & 0.02 & 0.01 & $9506 \cdot 15$ & 1.00 \\
\hline \multicolumn{6}{|c|}{ Outcome: BMI } \\
\hline Model $1^{*}$ & 3788 & 0.005 & 0.004 & $10770 \cdot 88$ & 1.00 \\
\hline Model $2 \dagger$ & 3345 & 0.02 & 0.01 & 9525.77 & 1.00 \\
\hline Model 3‡ & 3345 & 0.02 & 0.01 & 9523.82 & 1.00 \\
\hline
\end{tabular}

AIC, Akaike's information criterion; MSE, mean squared error

${ }^{*}$ Birth order and total siblings adjusted one for each other.

† Birth order and younger siblings adjusted for confounding variables: family income, maternal education, presence of the father, maternal skin colour, maternal age at birth, maternal height, gestational weight gain, pregnancy smoking consumption, pregnancy alcohol consumption, gestational systemic hypertension and gestational diabetes.

$\ddagger$ Total siblings adjusted for confounding variables: family income, maternal education, presence of the father, maternal skin colour, maternal age at birth, maternal height, gestational weight gain, pregnancy smoking consumption, pregnancy alcohol consumption, gestational systemic hypertension and gestational diabetes.

linear trend in males $(P<0 \cdot 001)$. Boys who had three or more siblings showed a decrease of $0.37 z$-scores (95\% CI -0.52 , $-0.23)$ in fat mass index compared to those who had no siblings. Fat-free mass index was associated with the total siblings only in girls $(P=0.035)$. Those with three or more siblings showed a 0.06 increase in $z$-score $(95 \%$ CI -0.04 , 0.17) compared to girls who had none. Moreover, the total siblings remained inversely related to $\mathrm{BMI}$ in males $(P<0 \cdot 001)$. Those boys with three or more siblings had a reduction of $0.39 z$-scores in BMI when compared to an only child (95\% CI $-0.55,-0 \cdot 22)$.
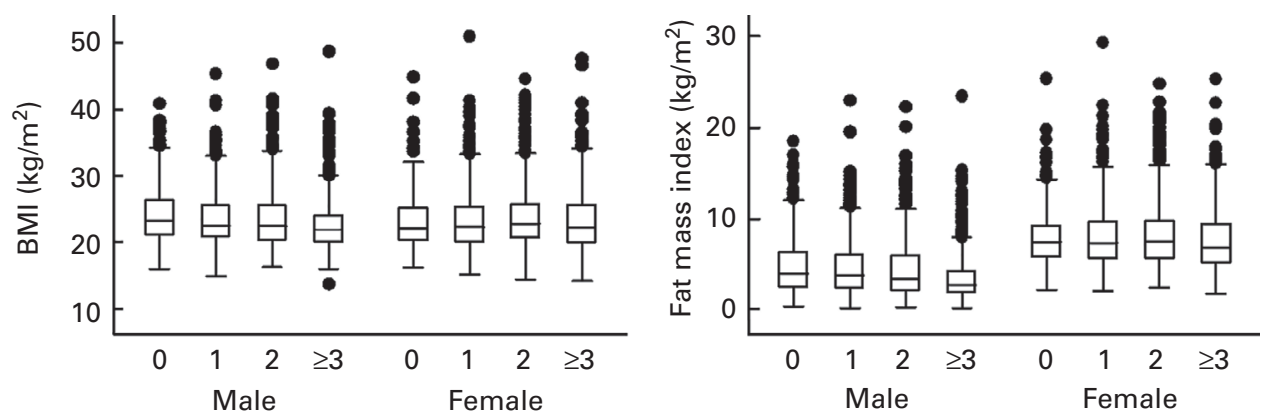

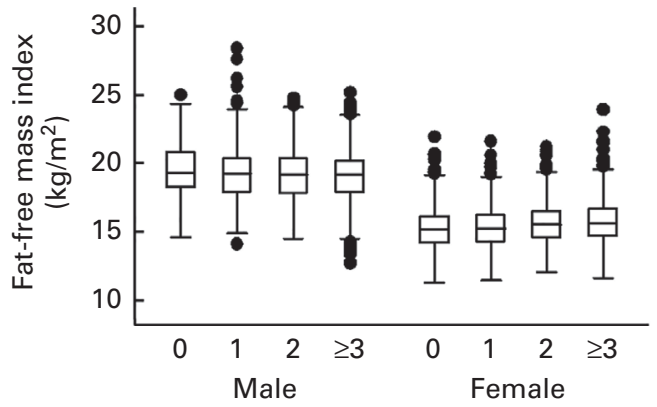

Fig. 2. Distributions of BMI, fat mass index and fat-free mass index, across total siblings, by sex. The 1993 Pelotas Birth Cohort, Brazil. 
Table 4. Crude and adjusted analyses of association between siblings and outcomes (in z-score) stratified by sex (The 1993 Pelotas Birth Cohort, Brazil) (Number of participants; $\beta$ coefficients and $95 \%$ confidence intervals)

\begin{tabular}{|c|c|c|c|c|c|c|c|c|c|c|c|c|c|c|}
\hline & \multicolumn{8}{|c|}{ Crude analyses } & \multicolumn{6}{|c|}{ Adjusted analyses* } \\
\hline & \multicolumn{4}{|c|}{ Male } & \multicolumn{4}{|c|}{ Female } & \multicolumn{3}{|c|}{ Male } & \multicolumn{3}{|c|}{ Female } \\
\hline & $n$ & $\beta$ & $95 \% \mathrm{Cl}$ & $P$ & $n$ & $\beta$ & $95 \% \mathrm{Cl}$ & $P$ & $\beta$ & $95 \% \mathrm{Cl}$ & Valor $P$ & $\beta$ & $95 \% \mathrm{Cl}$ & $P$ \\
\hline \multicolumn{15}{|l|}{$\begin{array}{l}\text { Outcome: fat } \\
\text { mass index }\end{array}$} \\
\hline Total siblings & & & & $<0.001 \dagger$ & & & & 0.023 & & & $<0.001 \dagger$ & & & 0.010 \\
\hline 0 & 213 & \multicolumn{2}{|c|}{ Reference } & & 245 & \multicolumn{2}{|c|}{ Reference } & & \multicolumn{2}{|c|}{ Reference } & & \multicolumn{2}{|c|}{ Reference } & \\
\hline 1 & 553 & -0.13 & $-0.26,-0.01$ & & 621 & 0.04 & $-0.09,0.18$ & & -0.13 & $-0.27,0.004$ & & 0.02 & $-0.13,0.16$ & \\
\hline 2 & 460 & -0.14 & $-0.27,-0.01$ & & 479 & 0.08 & $-0.06,0.22$ & & -0.14 & $-0.29,-0.01$ & & 0.05 & $-0.10,0.20$ & \\
\hline \multirow{2}{*}{\multicolumn{15}{|c|}{$\begin{array}{l}\text { Outcome: fat- } \\
\text { free mass } \\
\text { index }\end{array}$}} \\
\hline & & & & & & & & & & & & & & \\
\hline Total siblings & & & & 0.164 & & & & $<0.001 \dagger$ & \multirow{2}{*}{\multicolumn{2}{|c|}{ Reference }} & $0.083 \dagger$ & & & 0.035 \\
\hline 0 & 213 & \multicolumn{2}{|c|}{ Reference } & & 245 & \multicolumn{2}{|c|}{ Reference } & & & & & \multicolumn{2}{|c|}{ Reference } & \\
\hline 1 & 553 & -0.07 & $-0.19,0.05$ & & 621 & 0.01 & $-0.09,0.10$ & & -0.08 & $-0.20,0.04$ & & -0.01 & $-0.11,0.09$ & \\
\hline 2 & 460 & -0.09 & $-0.21,0.03$ & & 479 & 0.14 & $0.04,0.24$ & & -0.11 & $-0.24,0.01$ & & $0 \cdot 10$ & $-0.002,0.21$ & \\
\hline$\geq 3$ & 616 & -0.13 & $-0.24,-0.01$ & & 601 & 0.15 & $0.06,0.25$ & & -0.12 & $-0.25,0.01$ & & 0.06 & $-0.04,0.17$ & \\
\hline \multicolumn{15}{|l|}{$\begin{array}{l}\text { Outcome: } \\
\text { BMI }\end{array}$} \\
\hline Total siblings & & \multirow{2}{*}{\multicolumn{2}{|c|}{ Reference }} & $<0.001 \dagger$ & & \multirow{2}{*}{\multicolumn{2}{|c|}{ Reference }} & 0.145 & \multirow{2}{*}{\multicolumn{2}{|c|}{ Reference }} & $<0.001 \dagger$ & \multirow{2}{*}{\multicolumn{2}{|c|}{ Reference }} & 0.067 \\
\hline 0 & 213 & & & & 245 & & & & & & & & & \\
\hline 1 & 553 & -0.15 & $-0.30,-0.01$ & & 621 & 0.04 & $-0.12,0.20$ & & -0.16 & $-0.31,0.001$ & & 0.01 & $-0.15,0.18$ & \\
\hline 2 & 460 & -0.17 & $-0.32,-0.02$ & & 479 & 0.15 & $-0.01,0.31$ & & -0.19 & $-0.36,-0.03$ & & $0 \cdot 10$ & $-0.07,0.27$ & \\
\hline$\geq 3$ & 616 & -0.41 & $-0.55,-0.26$ & & 601 & 0.02 & $-0.14,0.18$ & & -0.39 & $-0.55,-0.22$ & & -0.09 & $-0.26,0.09$ & \\
\hline
\end{tabular}

${ }^{\star}$ For family income, maternal education, presence of the father, maternal skin colour, maternal age at birth, maternal height, gestational weight gain, pregnancy smoking consumption, pregnancy alcohol consumption, gestational systemic hypertension and gestational diabetes.

† Linear trend test. 
Similar results were found in a study in India with women only, which showed a negative correlation between number of siblings and both fat mass and fat-free mass. However, the Indian study was not adjusted for potential confounding factors and body composition was assessed by skinfold thickness ${ }^{(21)}$. Studies that assess the body composition of adolescents using reference measurement methods are still rare in the literature, which hinders the comparison of results.

Concerning BMI, it was shown that this variable remained inversely associated with the number of total siblings in males in the adjusted analysis. One possible explanation for this association is that the greater number of siblings leads to an increase in family size, which has an inverse effect on family income and, consequently, on obesity. According to a study conducted in Brazil, there is a direct association between income and obesity in adolescents of both sexes ${ }^{(22)}$.

Corroborating the results of the present study, a longitudinal study conducted in the USA showed that only children had higher mean BMI compared to those who had at least two brothers, even after adjustment for possible confounding factors $^{(5)}$. Other studies analysing overweight and/or obesity in adolescents, using different methods ${ }^{(23-25)}$, observed inverse associations between number of siblings and overweight and/or obesity, with only children having a higher prevalence of overweight and obesity when compared with individuals who had siblings ${ }^{(3,4,6,7,26)}$. In contrast, Hesketh and colleagues ${ }^{(27)}$ showed no association between number of siblings and overweight in Chinese adolescents. Results of stratified analysis by sex are presented for one study only ${ }^{(4)}$ which hinders the comparison of findings.

Some limitations in the present study should be highlighted. First, as with any longitudinal study, potential selection biases due to loss to follow-up are a substantial limitation. To help address this concern, we compared the sample participants with the original participants examined in 1993. Adolescents with worse socioeconomic and nutritional profiles were slightly less likely to be followed up. Socioeconomically intermediate participants were more likely to located as compared with very poor or very rich adolescents $(81.8 v$. 75.6 and $76.1 \%$, respectively). Furthermore, participants whose mothers had no schooling were less likely to be followed up compared to those whose mothers had 9 or more years of schooling (69.4 $v$. $77.5 \%)$. However, the magnitude of such differences is modest, therefore minimising the likelihood of bias ${ }^{(18)}$.

Another limitation is the lack of information on the number of siblings of adolescents at 18 years of age, which limits us to the information collected at the 15-year-old follow-up. Finally, the measurements of body composition are only available at age 18 years; therefore, we were not able to investigate the development of body composition across the entire life course.

Strengths of the present study include its prospective design, the use of air displacement plethysmography (BOD POD $^{\circledR}$ ) as a method for assessing body composition, and the high follow-up rate at age 18 years $(81 \cdot 3 \%)$ ensuring the representativeness of the sample despite some small differences between study participants and those lost to follow-up.

In conclusion, only children of both sexes are more likely to have higher fat mass index compared to those who have siblings. Girls who have no siblings present the lowest levels of fat-free mass, while only boy children have greater BMI.

Given the reduction in the fertility rate in Brazil and in the world $^{(1,2,28,29)}$ and the larger number of couples choosing to have an only child ${ }^{(29)}$, our research further highlights the need for prevention of obesity or fat mass accumulation in adolescents who are only children.

\section{Acknowledgements}

All colleagues and workers who contributed to the study included since its 1 st year.

The 1993 birth cohort study is currently supported by the Wellcome Trust through the programme titled 'Major Awards for Latin America on Health Consequences of Population Change'.

Contributions of authors are as follows: F. O. M. was responsible for the literature review, results analysis, data interpretation and writing of the paper; M. C. F. A., F. C. B. and D. L. D. helped with the overall concept of the paper, the design of the analysis, and writing of the paper; A. A. S., C. L. M. and A. J. D. B. contributed with the methodology issues and the data analysis. All authors discussed the results and implications and commented on the manuscript at all stages.

The authors declare that they have no conflicts of interest.

\section{References}

1. The Brazilian Institute of Geography and Statistics (2000) 2000 Census. IBGE. http://www.ibge.gov.br/english/ estatistica/populacao/default_censo_2000.shtm

2. The Brazilian Institute of Geography and Statistics (2010) 2010 Census. IBGE. http://www.ibge.gov.br/english/ estatistica/populacao/censo2010/default.shtm

3. Haugaard LK, Ajslev TA, Zimmermann E, et al. (2013) Being an only or last-born child increases later risk of obesity. PLOS ONE 8, 1-8.

4. Wang H, Sekine M, Chen X, et al. (2007) Sib-size, birth order and risk of overweight in junior high school students in Japan: results of the Toyama Birth Cohort Study. Prev Med 44, 45-51.

5. Chen AY \& Escarce JJ (2010) Family structure and childhood obesity, Early Childhood Longitudinal Study - Kindergarten Cohort. Prev Chronic Dis 7, 1-8.

6. Gopinath B, Baur LA, Burlutsky G, et al. (2012) Socioeconomic, familial and perinatal factors associated with obesity in Sydney schoolchildren. I Paediatr Child Health 48, 44-51.

7. Guedes DP, Rocha GD, Silva AJ, et al. (2011) Effects of social and environmental determinants on overweight and obesity among Brazilian schoolchildren from a developing region. Rev Panam Salud Publica 30, 295-302.

8. Celi F, Bini V, De Giorgi G, et al. (2003) Epidemiology of overweight and obesity among school children and adolescents in three provinces of central Italy, 1993-2001: study of potential influencing variables. Eur J Clin Nutr 57, 1045-1051.

9. Dahly DL \& Adair LS (2010) Does lower birth order amplify the association between high socioeconomic status and central adiposity in young adult Filipino males? Int $J$ Obes (Lond) 34, 751-759. 
10. Siervo M, Horta BL, Stephan BC, et al. (2010) First-borns carry a higher metabolic risk in early adulthood: evidence from a prospective cohort study. PLOS ONE 5, 1-7.

11. Stettler N, Tershakovec AM, Zemel BS, et al. (2000) Early risk factors for increased adiposity: a cohort study of African American subjects followed from birth to young adulthood. Am J Clin Nutr 72, 378-383.

12. Li C, Goran MI, Kaur H, et al. (2007) Developmental trajectories of overweight during childhood: role of early life factors. Obesity (Silver Spring) 15, 760-771.

13. Wells JC, Hallal PC, Reichert FF, et al. (2011) Associations of birth order with early growth and adolescent height, body composition, and blood pressure: prospective birth cohort from Brazil. Am J Epidemiol 174, 1028-1035.

14. Karn MN \& Penrose LS (1951) Birth weight and gestation time in relation to maternal age, parity and infant survival. Ann Eugen 16, 147-164.

15. Roberts DF \& Tanner RE (1963) Effects of parity on birth weight and other variables in a Tanganyika Bantu sample. Br J Prev Soc Med 17, 209-215.

16. Wilcox MA, Chang AM \& Johnson IR (1996) The effects of parity on birthweight using successive pregnancies. Acta Obstet Gynecol Scand 75, 453-459.

17. Hallal PC, Wells JC, Reichert FF, et al. (2006) Early determinants of physical activity in adolescence: prospective birth cohort study. BMJ 332, 1002-1007.

18. Goncalves H, Assuncao MC, Wehrmeister FC, et al. (2014) Cohort profile update: the 1993 Pelotas (Brazil) Birth Cohort follow-up visits in adolescence. Int J Epidemiol 43, $1082-1088$

19. Victora CG, Araujo CL, Menezes AM, et al. (2006) Methodological aspects of the 1993 Pelotas (Brazil) Birth Cohort Study. Revista de saude publica 40, 39-46.
20. VanItallie TB, Yang MU, Heymsfield SB, et al. (1990) Heightnormalized indices of the body's fat-free mass and fat mass: potentially useful indicators of nutritional status. Am J Clin Nutr 52, 953-959.

21. Ghosh JR \& Bandyopadhyay AR (2006) Income, birth order, siblings, and anthropometry. Hum Biol 78, 733-741.

22. The Brazilian Institute of Geography and Statistics (2010) Consumer Expenditure Survey - POF 2008-2009: anthropometry and nutritional status of children, teenagers and adult in Brazil. IBGE. http://www.ibge.gov.br/english/ estatistica/populacao/condicaodevida/pof/2008_2009_encaa/ default.shtm

23. Cole TJ, Bellizzi MC, Flegal KM, et al. (2000) Establishing a standard definition for child overweight and obesity worldwide: international survey. BMJ 320, 1240-1243.

24. Knudsen LB (1998) The Danish fertility database. Dan Med Bull 45, 221-225.

25. World Health Organization (2007) Growth Reference Data for 5-19 years. Geneva: World Health Organization.

26. Mushtaq MU, Gull S, Shahid U, et al. (2011) Family-based factors associated with overweight and obesity among Pakistani primary school children. BMC Pediatr 11, 114.

27. Hesketh T, Qu JD \& Tomkins A (2003) Health effects of family size: cross sectional survey in Chinese adolescents. Arch Dis Child 88, 467-471.

28. World Bank (2012) World development indicators database http://data.worldbank.org/indicator/SP.DYN.TFRT.IN/countries/ $1 \mathrm{~W}-U S-E U$ ?display= graph

29. The Brazilian Institute of Geography and Statistics (2013) Synthesis of social indicators: an analysis of the living conditions of the Brazilian population. IBGE. http:// www1.ibge.gov.br/english/estatistica/populacao/condicao devida/indicadoresminimos/ 